\title{
WATER PRODUCTIVITY, EXPLOITATION AND FOOTPRINT: OBSOLETE CONCEPTS OR REPRESENTATIVE TOOLS IN UNDERSTANDING EUROPEAN ENVIRONMENTAL POLICY?
}

\author{
ANDREI, J. V..$^{*}$ - BĂLĂCESCU, A. ${ }^{2}-$ CHIVU, L ${ }^{3}-$ GOGONEA, R. M. ${ }^{3}-$ PATRASCU, A. ${ }^{1}-$ \\ ZAHARIA, M. ${ }^{1}$ \\ ${ }^{I}$ Petroleum - Gas University of Ploiesti, Faculty of Economic Sciences \\ B-dul Bucuresti, No.39, 100680 Ploiesti, Prahova, Romania \\ ${ }^{2}$ Faculty of Economics, Constantin Brâncuşi University of Targu Jiu, Gorj County, Romania \\ ${ }^{3}$ National Institute for Economic Research - Romanian Academy \\ Calea 13 Septembrie 13, Casa Academiei Romane, 050711 Bucharest, Romania \\ ${ }^{4}$ Faculty of Cybernetics, Statistics and Economic Informatics, The Bucharest University of \\ Economic Studies, No.6, Piata Romana, 010374 Bucharest, Romania \\ *Corresponding author \\ e-mail: andrei_jeanvasile@yahoo.com; phone: +40-72-761-5540
}

(Received $7^{\text {th }}$ Feb 2021; accepted $16^{\text {th }}$ Apr 2021)

\begin{abstract}
In contemporary economies, water represents a key resource in ensuring the sustainable economic development, being equally a factor of production in the economic branches, and also a relevant indicator in shaping the evolution of human activity. Water resources are vital for humanity, ecosystems and the economy, and its inefficient use is a serious problem. The main aim of the present research was to analyse and evaluate the impact of water use, from the perspective of a sustainable economic development, and to determine to what extent it can become a relevant indicator in this respect. For this purpose, three indicators were considered: water productivity, water exploitation index and water footprint. Based on the findings highlighted in the research, it can be concluded that the considered indicators can constitute representative instruments in understanding the European environmental policy.

Keywords: aquatic systems, ecosystem, environmental efficiency, hydrographic shortage, water management, water deficit, pollution, sustainability
\end{abstract}

\section{Introduction}

In the context of contemporary economic evolutions marked by increasingly pronounced manifestations of some negative climatic phenomena the reconsideration of the water resource management and its adaptation to the new global exigencies became mandatory. It also emphasized the necessity for an integrative approach in regard to these resources. Water use analysis is a mandatory instrument of sustainable development. It may serve as a sensitive compass ready to show the degree of economic growth, and as an instrument orienting decision makers to those economic policies that do not ignore the limited nature of this resource, all while recognising the need to reconcile accessibility to water.

The worsening of the water deficit, wastefulness, reckless pollution of water sources, the ever-increasing length of droughty periods, the poor management for water, the irresponsible catchment of flowing water are all arguments in favour of a new approach to water management as a way to ensure the balanced development of economic activities, and a sustainable future of human communities. The misuse of water 
resources may have serious and irreversible effects on economies and societies: it may jeopardise very existence of industries relying on intensive use of water, or it may cause, by depletion, the abandonment of entire geographic areas.

In this context, the water footprint may be viewed as one of the specific analytical indicators of social and economic development, and, no less, as a challenge for experts, because this indicator must be able to reveal, as true to fact as possible, the complex aspects of the quality of human life, accepting the prerequisite that water is both an economic resource (Winpenny, 2005), and a vital source of life (Oki and Kanae, 2006). This may be equally a challenge to experts, because the indicator must be able to reflect the complex aspects of human life in a realistic manner, knowing that water is not only an economic resource, but also the vital source of human life, and that we are already witnessing the globalisation of the water issue. This, in turn, reflects on the environmental challenges affecting societies and economies, and therefore requires a multidisciplinary and trans-societal approach (Hogeboom, 2020).

The debate on water use as a possible indicator which reflects the sustainability of the economic development returns in the literature with a new perspective, following the transformations of the paradigms of reference for the contemporary society. The interdependence between the sustainable management of water and economic development is obvious and holds the attention of the dedicated literature. It is generally recognised that irresponsible consumption and wasteful use of water are two factors that add to the already existing pressure on the uncontrollable exploitation of ground and surface water. The reckless use of water generates a wide range of risks and vulnerabilities in contemporary economies, from the irreversible degradation of the environment, or the appearance of an unsustainable cycle of economic and social activities, or even social unrest, to jeopardising food safety and security, or endangering aquatic systems and landscapes.

The literature related to this subject (EESC, 2013; Sima and Gheorghe, 2015; D'Ambrosio et al., 2020) is unanimous in asserting the vital role of water in supporting life, human activities, nature, and economy. Although permanently regenerated in its natural circuit, water is however a limited resource that cannot be replaced or substituted for.

With all these aspects in mind, understanding water and its specific indicators as possible instruments for the determination of the level of economic development is part of the attempts of identifying indicators relevant for measuring sustainable development, in close connection with the global changes in the paradigm of contemporary economy. As Wada et al. (2016) pointed out, water consumption by humans in the $20^{\text {th }}$ century grew six times as a consequence of the Globe's fourfold population increase, and the rising of its standard of living. This increased the pressure on the water resources, through even more waste. From this perspective, the concept of water footprint (WF) may gain recognition as an instrument orienting towards more sustainable water use patterns and consumption habits (Aldaya et al., 2010).

Starting from the realities of the contemporary economy, the concepts of water footprints and the efficiency of water use can join the concept of sustainable economic growth, taking into consideration that water resources are indispensable to the evolution and the development of the human society.

The water footprint can represent a much more comprehensive and complex concept (Jean et al., 2018; Gogonea, 2019), of multidimensional nature which also implies different interpretations and meanings, compared to the classical indicators for 
measuring sustainable development. The necessity of changing the referential imposed by the current economic demands requires the approach of the human system from the perspective of its relations with the ecosystem, and the water footprint can realize this sort of connection.

The responsible management and use of water resources have become one of the most provocative challenges the contemporary society is facing, in the context of the necessity to adapt to the new transformations and requirements of sustainable economic development. Starting from the fact that the environment represents a fundamental element of sustainable development, which should not be understood only as a source of production factors or a support element for the human activity, but also as a result of the complexity of the evolution of the contemporary society, environment has become a topical issue which regards the identification of those relevant factors imprinting the evolution of the current global economic transformations. From this perspective, the problematic of the efficient use of water, and also the identification of certain reliable indicators which would allow the mapping of this resource is of actuality and widely debated in the specialized studies, highlighting numerous correlations, limits and interdependencies between the multiple aspects of sustainable development. Thus, numerous researches have analysed the efficiency of water use as a significant component of the environment, at territorial level (Dietzel et al., 2016; Hernández et al., 2015; Andrei et al., 2020). However, there is also a certain limit, respectively the efficiency of water use cannot be measured directly on a global scale, which requires the deepening of the knowledge and management of the water processes (Xiao et al., 2013), simultaneously with the development of the remote sensing technology.

The responsible management of water resources, but also the efficiency of its use are fundamental and of major importance due to the fact that water represents a vital resource for humans and ecosystems, but with a tendency of becoming an economic asset under the conditions of an increasingly insufficient access to safe, clean water at an affordable price for the population which has become more and more numerous. As observed by Vörösmarty et al. (2015), the local water consumption has become a global problem, requiring global approaches.

The transfer and relocation of water implies not only the realization of certain substantial and long-term investments but can also irremediably affect the environment and the natural habitats. Meanwhile, water is indispensable in carrying out the activities for all economic sectors, but the most consuming economic branches, as proved by a number of specialized studies, are agriculture and manufacturing, a fact that determined us to consider them for this research. In this context, regional and global analyses have become more and more relevant for a domain in which water is understood not only from the perspective of a rational economic use, but also as a vital source, indispensable for human evolution. Considered to be a significant component of the environment, water as an economic resource can be analysed and understood through certain important indicators such as: water productivity (WP) and water exploitation index (WEI).

As Lipinska (2016, p. 114) notes the high intensity of the water resources exploitation in the case of numerous European states, exposes these countries to incidence of phenomena such as 'severe water scarcity' or 'water scarcity'. In line with this approach, Arnel et al. (2011) argues that European countries do not always use water efficiently, in order to contribute in reducing the access and the availability of 
water resources, or by contrary their behaviour provoke even dramatically impact on climate changes.

The water deficit, doubled by the inconsistency of the management measures taken to protect this strategic resource emphasizes the necessity for a more thorough research in the field, and the application of new, environment-friendly technologies, in the domains with intense water consumption. The problematic generated by the water deficit has accentuated, as proved by the much more dynamic frequency of the drought periods and the extension of the geographic areas of manifestation of hydrographic shortage. From this perspective, the necessity of convergence, with a particular stress on the EU space, for the construction of a European model of sustainable development has brought to the fore the tools specific for footprints. Very often, the water footprint goes hand in hand with a carbon footprint (Kubova et al., 2018; Poom et al., 2017; Schlegel et al., 2016) or with the field footprint (Chen et al., 2018; de Ruiter, 2017).

The responsible management of water resources, the appropriate management of waste, the reduction of the greenhouse effect and of energy consumption, the sustainable exploitation of sources of energy, the protection of the environment and natural landscapes, are all important goals to be pursued for the purpose of ensuring the sustainable development of human society. This paper is intended as a background analytical research of the correspondence between the three indicators and the exigencies of a sustainable development in the two economic sectors chosen for this purpose: manufacturing and agriculture.

With the aid of the three indicators considered, water may act as a relevant sensor of the level of sustainable development and of the interaction between human existence and environment. As such, water can be used in practice as a scientifically reliable unit of measure for those aspects of real economy that are fundamental for the wellbeing of human condition. Therefore, water footprint, water productivity, and water exploitation are concepts that should not be regarded or understood as models or indicators per se, but rather as a complement to the ample debate pursuing to clarify the mechanisms that underlie sustainable development in our times, and to render efficiency to environmental policies. It is from this perspective that the title question arises: are these obsolete concepts or representative tools in understanding environmental policy?

Until now, the importance and usefulness of the water footprint as an indicator for the analysis of sustainable development has been insufficiently highlighted in the context of the indicators developed and diversified for the purpose. The literature is still endeavouring to find suitable indicators to measure the water consumption needed to manufacture a product or provide a service, but also capable to assess the environmental impact of various consumption and production patterns.

The study carried out and presented in the current article aimed at two complementary, interconnected objectives, respectively one prior to the analysis itself and another one, the main one, which took into consideration the analysis itself which meant the identification of the main realities and tendencies. The first objective is to emphasize the image regarding, on the one hand, the relation between water exploitation indices and its productivity, and on the other hand, the relations between internal water footprints used for the production of agricultural products and those used for the production of industrial ones. The second objective, the main objective of the study, was to identify and evaluate several possible relations between the internal water footprint used for the generation of a product and the efficiency of its utilization. To lay emphasis on the elements specified above, the article was structured in six sections: 
introduction, a systematic review of the specialized literature, the methodology used to validate the objectives proposed in the research, a section presenting the results obtained and the related discussions, and a section of conclusions and references. Also, an additional section of research limits and further directions of investigation was included in the article.

\section{Literature review}

The water footprint concept constitutes not only an opportunity to understand the water consumption from the perspective of sustainability and the choice of practices of responsible water use as sustained by Aldaya et al. (2010), but also constitutes an instrument of integrative knowledge of the aspects related to the water use in its close connection with the social challenges, the economic environment or related to ensuring sustainable economic development, as described by Chapagain and Tickner (2012).

The water footprint belongs to a much wider and diverse family of analytical instruments. It is the family of footprints, which complements and adds to a range of indicators that help us measure and understand the concepts of sustainability and wellbeing. A drawback but also an opportunity for research along this line is the very diversity of the methodologies used to give a scientific basis to such footprints, and their limited capacity to substantiate environmental policies and to integrate into the existing specific indicators. At the same time, as Chapagain and Tickner (2012) have also demonstrated, the water footprint with its various components can have a significant contribution to enriching and diversifying the knowledge about the closely-knitted connections between the use of water, sustainable economic development, and the contemporary social and environmental requirements.

The methodology based on the use of footprints has become a widespread instrument in the specialized studies, and is utilized to understand the different aspects regarding the sustainable development. The water footprint does nothing more than to complete this diverse scientific landscape, and contribute to the refining of the entire concept of sustainable development.

The concept of the water footprint was initially introduced in Hoekstra's study, in 2003, which proposed a specific indicator which would directly or indirectly measure the volume of freshwater consumed in order to produce goods or services consumed by an individual, a country, a community, a campaign or another organization. This indicator has been refined and supplemented by other methodologies specific to the domain such as Water Remaining (AWARE) method (Ansorge and Beránková, 2017) or water resources exploitation (WRE) (He et al., 2019). As shown in the literature (Harding, 2019), terms such as water footprint, water accounting, water use intensity, are used to describe the quantity of water used or incorporated to obtain a product, process or service, or as the case may be, the efficiency of water use.

Studies, such as the ones conducted by Lovarelli et al. (2016) and Jeswani and Azapagic (2011), analysing the existing approaches in the literature regarding the water footprint emphasize the strong points and the conceptual limitations, concluding that there are immense variations in the results obtained in these studies, as a cause of either the methodologies utilized, the data availability or other random causes. Returning to the water footprint and the efficiency of water use, the specialized literature has offered a wide range of studies, methodologies and areas to which this can be applied. 
Researches regarding the water footprint aimed especially at agriculture, as proven by Ewaid et al. (2019), Barbosa et al. (2017), Lovarelli et al. (2016) and Zhao and Chen (2014), taking into consideration the quantity of water used in this domain, the obtainment of animal products and their processing to which the animal husbandry processes can be added (Mourad et al., 2019; de Miguel et al., 2015; Lee et al., 2015).

Thus, Scheepers and Jordaan (2016) analysed the intensity of blue and green water use in the case of alfalfa used in the feeding of lactating cows, Owusu-Sekyere et al. (2016) quantified the amount of water used for the milk production and processing in South Africa, Zonderland-Thomassen and Ledgard (2012) used and compared in their study two methodologies for estimating the water footprint in the case of milk production in two regions of New Zeeland, Zoumides et al. (2014) economically evaluated the efficiency of water use for the production of several agricultural crops in Cyprus, Dourte et al. (2014) using a web-based tool estimated the water footprint of different agricultural products in different regions of the USA, and Chiu et al. (2015) calculated the water footprint in the case of second-generation bioethanol. In studies such as the one conducted by Borsato et al. (2018) Schafer and Blanke (2012) and Stoessel et al. (2012), both the water footprint and the carbon footprint generated during the production of numerous fresh agricultural products are calculated. Roibas et al. (2015) investigated the sustainability of banana culture systems in several organic plantations, from the perspective of the water use availability. Suttayakul et al. (2016), using the WFA methodology, quantifies in his research the volume of freshwater consumed and the degradation in the case of palm tree oil plantations. Page et al. (2012) concludes that the use and especially the efficiency of freshwater use is closely determined by the production system in use. Serio et al. (2018) applied the Grey Water Footprint $(\mathrm{GWF})$ for the determination of groundwater nitrate contamination level of soil, generated by agriculture in the Southern Apulia Region, Italy.

Several studies such as the ones elaborated by Ababaei and Etedali (2017) used the water footprint to estimate the production of wheat, barley and corn in Iran and as noted by Garofalo et al. (2019), in the case of Germany and Italy, two important countries in the winter wheat production, the emphasized models underlined a decrease of the future water footprint precisely due to the efficiency of water use and the improvement of the plants in water capitalization and the stocking of this resource in the soil.

In what regards the industry, Gerbens-Leenes et al. (2018) evaluated the water footprint in the case of two types of steel: alloyed and unalloyed, using the data from global databases available. Ma et al. (2018) and Gu et al. (2015), also evaluated the water footprint generated by the steel production in China, and Burchart-Korol and Kruczek (2015) evaluated the water deficit in the case of steel production in Poland. Similarly, Grey Water Footprint can be used to measure the level of contamination of water resources with pollutants that have a much higher noxious effect on health, such as: Mercury (Hg), Vanadium (V) and Ammonium $\left(\mathrm{NH}^{4+}\right)$, as Miglietta et al. (2017) argues.

However, there are studies such as Jamshidi (2019) which argue the limitations of the concept, that the water footprint measures only the quantities used in agriculture, manufacturing or households, without incorporating, for example, activities such as aquaculture (Vanham, 2016), which is strictly based on the use of water as a support. Taking into consideration the diversity of the elaborated studies focusing on water as a complement, our research comes to add to the range of specialized studies devoted to the evaluation of sustainable development from the perspective of the intensity of the 
use of this resource, trying to contribute to the expansion of the inventory of specific knowledge in the field.

As Hogeboom (2020) also suggests, there is an increasing number of studies in the literature, which use the concept of water footprint, in a variety of forms and applications that have been developed due to the complexity, gravity, and topicality of the critical issues arising from the need to manage and use water in a responsible manner. For example, according to the opinion of Gómez-Llanos et al. (2020), the water footprint has gained recognition as a multidimensional indicator for the direct measurement of the water consumption with the aid of the two parameters, blue and green water, but also as a measure of the pollution level, based on the grey water concept. WF tools, alongside with indicators like water productivity and water exploitation, may be regarded as representative tools in understanding environmental policy, as part of a general framework in which effort is being made to better understand and broaden the system of indicators needed to measure the environmental dimension of sustainable development.

\section{Research methodology}

The methodology applied in this manuscript for arguing the main objectives described in this research follows the concepts already described in previous studies as Andrei et al. (2018) and Andrei et al. (2020) with some particularities presented in this section. Also, the possible linkage and mutuality effects of water productivity, exploitation and footprint on understanding the tendencies and exigencies of the European environmental policy are analyzed using the comparative analysis of the absolute values of the considered indicators, recorded for each of the EU countries and the cluster methodology.

The first indicator used is water productivity (WP) indicates the quantity of economic production per cubic metre of freshwater extracted (Arnell et al., 2011) (in EUR per $\mathrm{m}^{3}$ ) emphasizing the efficiency of its use. In its evaluation, the water from any source of fresh water, permanently or temporarily, mining water, flowing water, as well as the water from precipitations is considered. For a more conclusive picture of the availability and the efficiency of the use of water resources, the study included the water exploitation index (WEI). WEI measures the total annual freshwater extraction in a country as a percentage of the long-term annual average (30 years) of available water from renewable freshwater resources (Sheikhipour et al., 2018; Visentin and Guilhoto, 2019; Eurostat, 2020a) and water from any freshwater source, permanently or temporarily, mining water, flowing water, as well as water from precipitations.

Internal water footprint of consumption of agricultural and industrial products (Hoekstra and Chapagain, 2006) includes water from internal sources and which is consumed for the production of industrial and agricultural products. This includes water from underground or surface resources (blue water), the amount of freshwater needed to assimilate pollutants in order to meet the quality standards specific to water (gray water), as well as rainwater (green water) in the case of agricultural production.

The data set employed in designed and emphasizing the main objectives asset and described in the current research were retrieved from Eurostat $(2020 \mathrm{a}, \mathrm{b})$ in case of water productivity and exploitation indicators. Some statistics related to water footprints are collected from a deviated case study of Mekonnen and Hoekstra (2011). The 
indicators to assess the water sustainability as representative tools in understanding European environmental policy were: water productivity, exploitation and footprints as they are described in Table 1.

The research is performed on the EU level for the countries where the data were available to estimate if the analyzed water indicators are obsolete concepts or representative tools in understanding European environmental policy. Then the results are discussed and compared in a larger framework in order to identify the determinants between water exploitation indices and its productivity, on one hand, and to evaluate several possible relations between the internal water footprint used for the generation of a product and the efficiency of its utilization the on the other hand.

The current study works with various water indicators and measurements analyzed in case of the EU countries. It was also taken into consideration the fact that data and information related to water footprint estimation are scarce in some EU countries, therefore, the analyses and discussions were limited and focused on to these aspects. Taking into consideration that out of the $27 \mathrm{EU}$ member states, for four states (Austria, Finland, Ireland and Italy) there is no available data on water productivity, they were not included in the analysis of the possible relations between the internal water footprint consumed for the production of agricultural and industrial products and the efficiency (the productivity) of its utilization. As data series used also included the UK, as well as the relationships existing at that time between the UK and the EU, we included UK in our analysis as well.

Taking these aspects into account, six indicators were used in the study. The abbreviations, their significance and their units of measurement are presented in Table 1 .

Table 1. Significance and units of measurement for the utilized indicators. (Source: authors based on Eurostat, 2020 a, b; Mekonnen and Hoekstra, 2011)

\begin{tabular}{c|c|c}
\hline Indicator & Significance & Unit \\
\hline WP & Water productivity & Euro per $\mathrm{m}^{3}$ \\
WEI & Water exploitation index & Percentage \\
GWFAP & Green Water footprint of consumption of agricultural products & $\mathrm{m}^{3} / \mathrm{yr} / \mathrm{cap}$ \\
BWFAP & Blue Water footprint of consumption of agricultural products & $\mathrm{m}^{3} / \mathrm{yr} / \mathrm{cap}$ \\
GyWFAP & Gray Water footprint of consumption of agricultural products & $\mathrm{m}^{3} / \mathrm{yr} / \mathrm{cap}$ \\
BWFIP & Blue Water footprint of consumption of industrial products & $\mathrm{m}^{3} / \mathrm{yr} / \mathrm{cap}$ \\
GyWFIP & Gray Water footprint of consumption of Industrial products & $\mathrm{m}^{3} / \mathrm{yr} / \mathrm{cap}$ \\
\hline
\end{tabular}

An overview regarding the relations between the water exploitation indices and its productivity, as well as the relations between the internal water footprints used to obtain agricultural products and those used to produce industrial products, was emphasized by applying a quantitative descriptive method. This method is based both on the comparative analysis of the absolute values of the six indicators, recorded in each of the states included in the study, as well as through the relations between them.

To achieve the second objective of this study, the identification and the evaluation of several correlative relations between the internal water footprint used for the production of products and the efficiency of its use, the cluster methodology was used. For this purpose, starting from the vectors corresponding to the six indicators analysed above, the matrix $\mathrm{Z}$ was constructed. 


$$
Z=\left\|z_{i j}\right\| \underset{j=\overline{i, 6}}{j=1,24}
$$

Proximity matrix was obtained using Euclidian distance:

$$
W=\left\|w_{j l}\right\|_{j=\overline{1,24}, l=\overline{1,24}}, \quad w_{j l}=\sqrt{\sum_{j=1}^{24}\left(z_{i l}-z_{i j}\right)^{2}}, i=\overline{1,6}, l=\overline{1, p}, j \neq i, k \neq i, w_{i i}=0
$$

In Equation 1, $d_{i j}$ represents the square average of the sum of the square differences between each of the six types of water footprint of national consumption per capita registered in the countries $\mathrm{i}$ and $\mathrm{j}$.

Ward's method was generated to determine the distance between clusters (Gogonea, 2019):

$$
\Delta(A, B)=\sum_{i \in A \cup B}\left\|x_{i}-m_{A \cup B}\right\|^{2}-\sum_{i \in A}\left\|x_{i}-m_{A}\right\|^{2}-\sum_{i \in B}\left\|x_{i}-m_{\mathbf{B}}\right\|^{2}-\frac{n_{A \cap B}}{n_{A \cup B}}\left\|m_{A}-m_{B}\right\|^{2}
$$

In Equation 2, $\mathrm{A}$ and $\mathrm{B}$ are two clusters, $m_{i}$ is the centroid, $n_{i}$ is the number of elements from cluster $i$. and $x_{i}$ an item. Levene's Test and Robust Tests of Equality of Means were used to choose the method for testing the significance of the six variables at the clusters.

Let be a group in r clusters. The null hypothesis of Levene's Test is:

$$
H_{0 \_}: \sigma_{1}^{2}=\sigma_{2}^{2}=\sigma_{3}^{2}=\ldots=\sigma_{r}^{2}
$$

The acceptance condition of the null hypothesis $\mathrm{H}_{0_{-} 1}$ is:

$$
\text { Sig.F }>\alpha \text { equivalent to } F_{\text {stat }}<F_{\alpha, r-1, n-r}
$$

In case of accepting the null hypothesis (Eq. 3) the methodology ANOVA can be applied to test the statistical significances of the appurtenance of the variables to the clusters. Otherwise, we analyse the results of Robust Tests of Equality of Means, whose null hypothesis is:

$$
H_{0 \_}: m_{1}=m_{2}=m_{3}=\ldots=m_{r}
$$

The acceptance condition of the null hypothesis $\mathrm{H}_{0 \_}$is the same $(E q .4)$. In case of accepting the null hypothesis $\mathrm{H}_{0-2}$, it results that the averages of the variables at cluster level do not differ significantly and the appurtenance of the variables to the clusters is significant. Consequently, the appurtenance of the variables to the clusters is significant only if for all the six variables the hypothesis $\mathrm{H}_{0 \_} 2$ is rejected.

For the validation of statistical hypothesis, the Confidence level of $95 \%(\alpha=0.05)$ was used. In exceptional cases, the Confidence level of $90 \%(\alpha=0.10)$ was also admitted. The lack of a standardized approach to the special changes regarding the water availability in dynamic environments allows the analysis of the capacity to 
evaluate the ecological impact of the changing of water availability, prioritizing the sustainable management strategies of water capitalization, of the efficiency of its use.

\section{Results and discussion}

The distribution of the forms of relief, as well as the climatic conditions in the European states make the sources and the water reserves of each country differ significantly. Starting from the assumption that the abundance or lack of this resource can lead to different attitudes about the efficiency of its use from one state to another, a first analysis aimed to identify, on the one hand, both the water reserves (water obtained from lakes, artificial basins, rivers and underground) used by each of the 23 countries included in the research, and on the other hand the efficiency of the water quantities used.

In this case the two indicators (WEI and WP) show significant differences between the countries analysed and presented in Figure 1. A first observation is that there are countries with significant water reserves, which record very low productivity levels: Bulgaria 7.9 euro $/ \mathrm{m}^{3}$, Estonia $11.6 \mathrm{euro} / \mathrm{m}^{3}$, Greece $16.4 \mathrm{euro} / \mathrm{m}^{3}$. At the same time, there are countries with small water reserves, which use them in very large proportions as in case of Malta, $49.7 \%$ and Cyprus, $72.3 \%$ and have much higher productivity values (Malta $229.3 \mathrm{euro} / \mathrm{m}^{3}$ ).

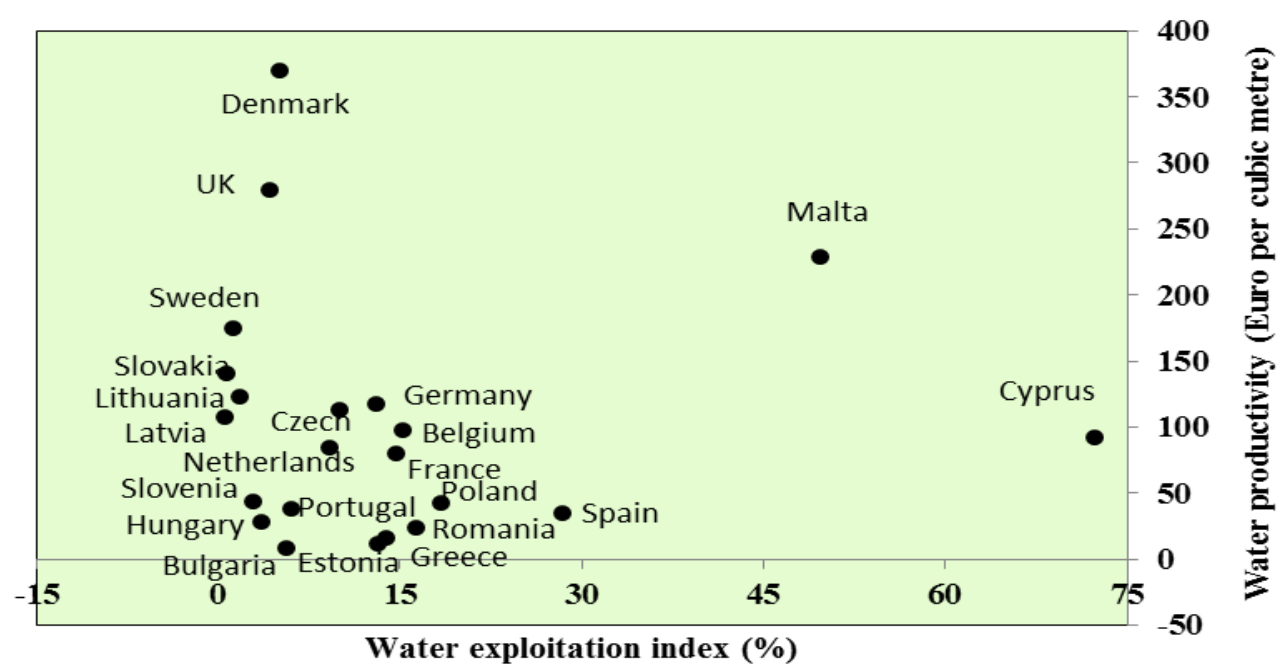

Figure 1. Water exploitation index vs. water productivity. (Source: authors' own design)

This is also emphasized by Lipinska (2016) who also points out that Malta and Cyprus are island nations with severe water scarcity but some countries like Sweden, Slovakia, Latvia and Croatia are countries in the bottom 1\% of the WEI and they are not experiencing water-stress challenges. In this regard, it should be underlined that, a value of the water exploitation index of over $20 \%$ implies that the water resource is under stress, but over $40 \%$ indicates stress and even severe stress regarding its most efficient use (Raskin et al., 1997).

A second observation highlights the fact that there is no determination between the percentage of water exploitation and its productivity, which leads to the conclusion that the efficiency of water use is not given by the restrictive nature of this resource in some 
European countries but by the quality and productivity of the technologies used in the production processes of manufacturing and agriculture. This conclusion is strongly supported by the position of Denmark, the European leader in the sustainable water use (370 euro/m3), which uses only $5 \%$ of the water supply in the production processes. Denmark is followed by the UK with a productivity of 280 Euros $/ \mathrm{m}^{3}$ and Sweden with 175 Euros $/ \mathrm{m}^{3}$, although they consume only $4.2 \%$, respectively $1.2 \%$ of their water reserves.

Regarding the ratio between the indicators Blue water footprint of consumption of agricultural products and Blue water footprint of consumption of industrial products (Fig. 2), it can be noted that, countries from southern Europe (Cyprus, Greece, Spain, Portugal) are detaching clearly compared to the other EU member countries, as the values recorded for the two variables in these countries are extremely different from those recorded by the other EU countries. Spain is the most arid country of the European Union and the one that devotes most of the water resources to irrigation, which has led to the development of the agri-food system (Clar et al., 2017) involving pressures on water.

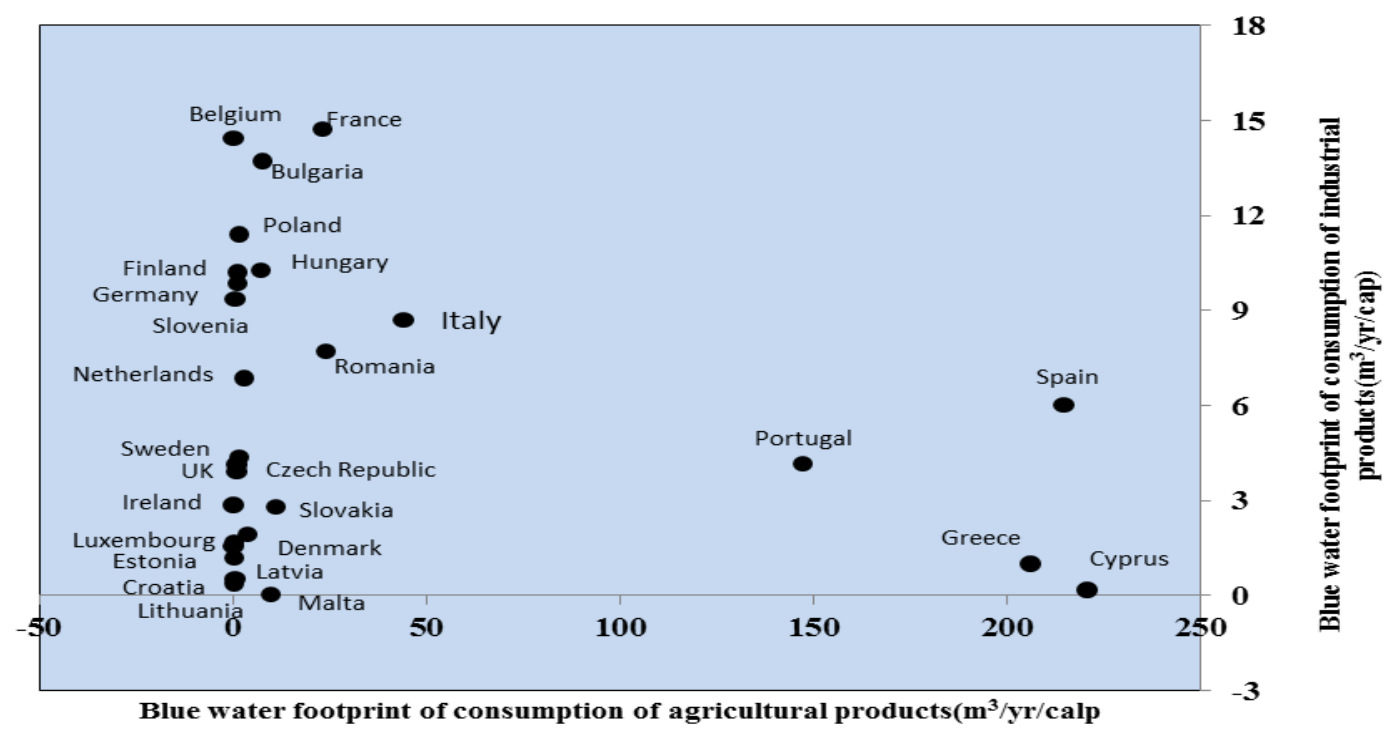

Figure 2. Agricultural products vs. industrial products blue water footprints. (Source: authors' own design)

The abstraction of water for industrial use has decreased in the last 2 two decades, partly due to the general decrease of the heavy industry as an intensive water consumer, but also due to the increase of the efficiency of water use as a result of the implementation of advanced cooling technologies that require less water. In the top of the EU countries, the highest water consumption values for agricultural and industrial products from the blue water footprint are recorded in Belgium and France, followed by Bulgaria.

Belgium is the country where industrial production uses the largest share of the total water footprint in the country. The water footprint of industries in Belgium measured between 1996 and 2005; used $41 \%$ of the total water footprint in the country, and the agricultural production used 53\% (Hoekstra and Mekonnen, 2012). 
The blue water footprint of production in France is dominated by consumption for agricultural products, especially maize. Other crops with a significant share in the blue water footprint are fodder crops, potato, soy, rice and apples. The priority basins, as regards the blue water footprint of the French production, are the Loire, Garonne, Seine and Rhone basins.

A marked deficit of Blue water footprint of consumption of agricultural products and Blue water footprint of consumption of industrial products can be found in countries such as Malta, Lithuania, and Croatia. In fact, Malta has the highest level of external water dependence (92\% dependence), its freshwater supply coming from other countries.

The spatial distribution of Gray Water footprint of consumption of agricultural and industrial products in UE is shown in Figure 3. This highlights substantial differences in the Gray Water footprint of consumption of agricultural and industrial product in Europe. Thus, Bulgaria is the largest consumer of gray water, largely due to agricultural products, while Germany is one of the main consumers of gray water in economic sectors such as: agriculture, food, textile and electricity. In turn, Poland is the largest supplier of gray water included in the exports of agricultural and chemical products to Germany and other European countries (Serrano et al., 2016).

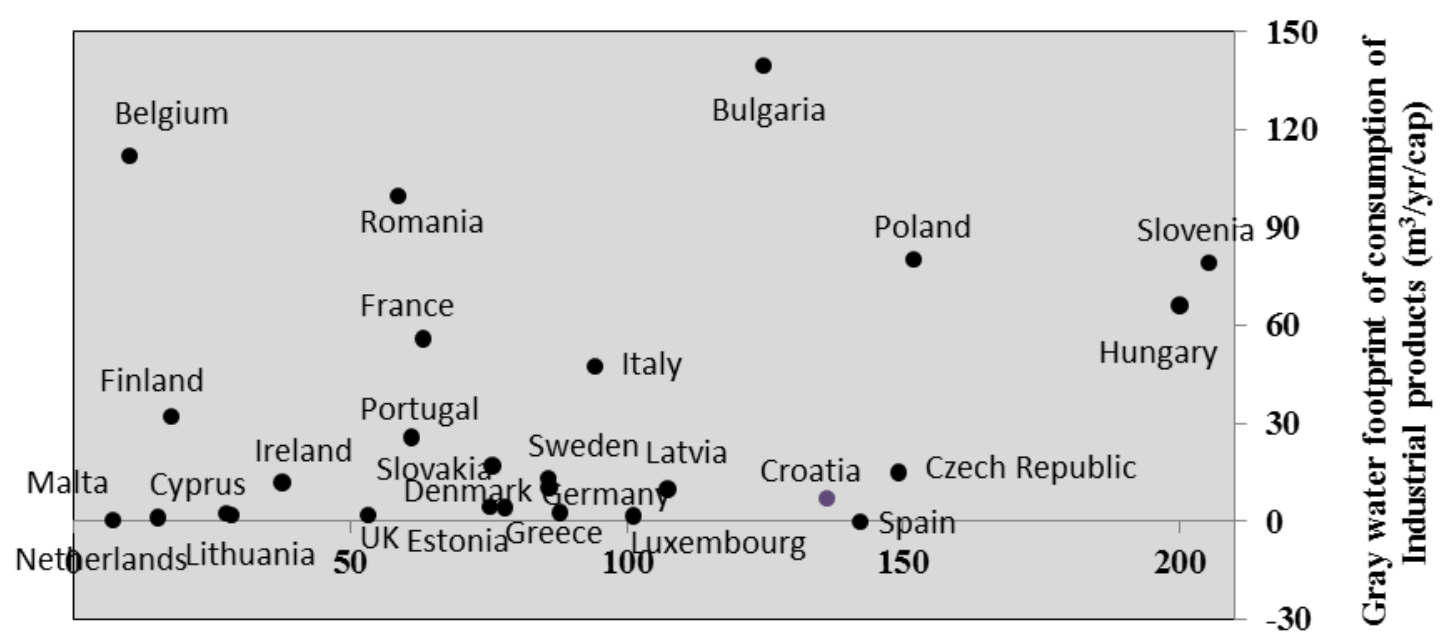

Figure 3. Agricultural products vs. industrial products gray water footprints. (Source: authors' own design)

The second part of the study aimed to identify the grouping mode of the 23 states in clusters, taking into account five indicators: WEI, GWFAP, BWFAP, GyWFAP, BWFIP, and GyWFIP. The dendrogram associated with the hierarchical clustering analysis developed as in Marinoiu (2016) and Andrei et al. (2018) is shown in Figure 4. The dendrogram shows the evolution of the states analysed by clusters, based on the similarity between them revealed by the indicators applied to the analysis.

According to Figure 4, the first level of grouping comes with six groups, each of them formed of two states (Slovakia, Sweden; Estonia, Lithuania; Denmark, UK; Germany, The Netherlands; Greece, Portugal; Poland, Slovenia), and a cluster formed of three states (Croatia, Latvia and The Czech Republic), while the other states are left outside any cluster. The second level of grouping already forms Cluster C1 (Denmark, 
Malta and UK), Cluster C2 (Croatia, The Czech Republic, Estonia, Latvia, Lithuania, Slovakia and Sweden), Cluster C4 (Cyprus, Greece, Portugal and Spain), and two other clusters, one formed of Belgium and France, and the other formed of Romania and Bulgaria. Finally, at the next level of grouping, the clusters formed of Belgium-France and Germany-The Netherlands group into Cluster C3, and the clusters RomaniaBulgaria and Poland-Slovenia, together with Hungary, form Cluster C5.

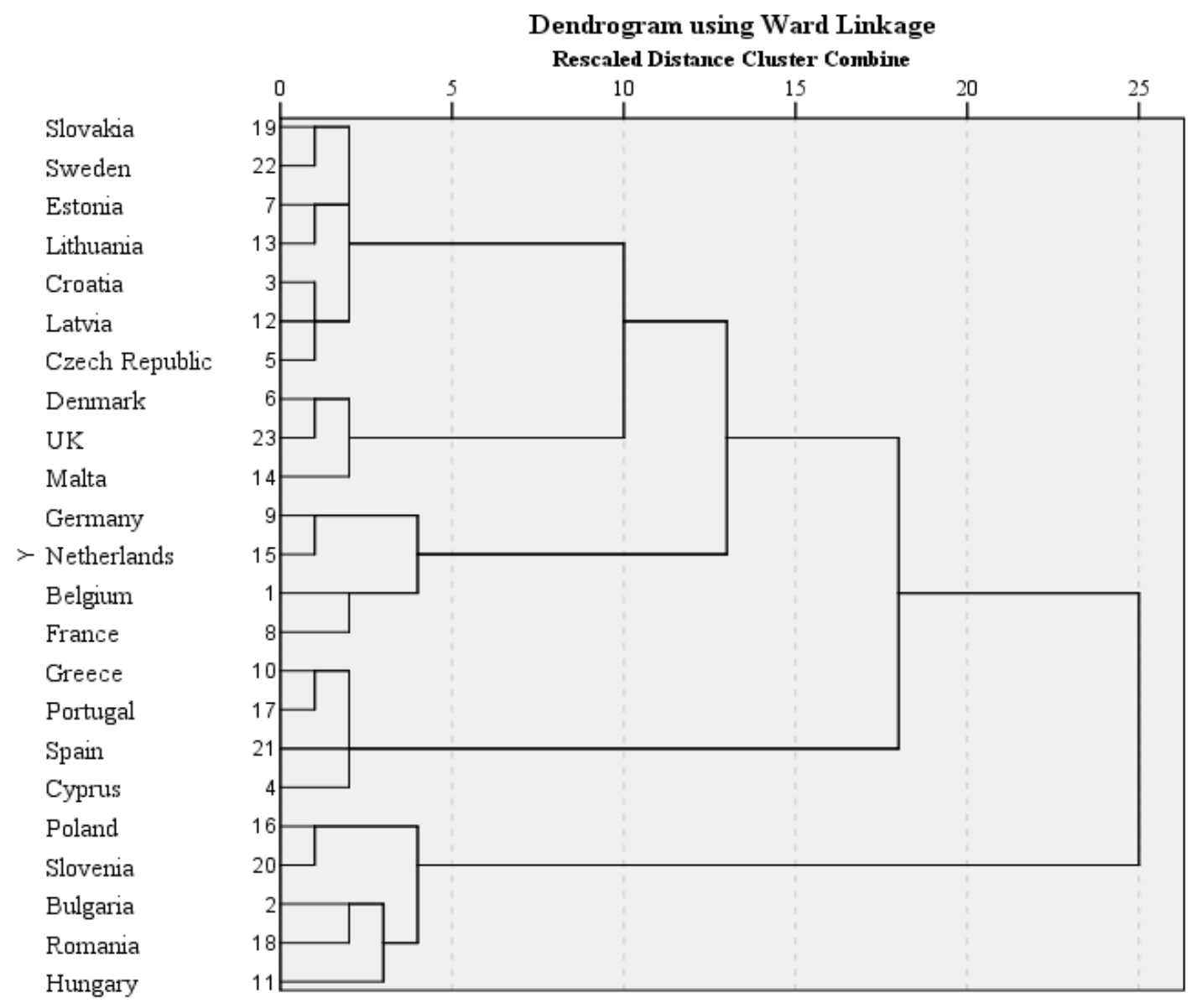

Figure 4. The cluster generation dendrogram using Ward Linkage Method. (Source: authors' own design)

Following the tests and analyses carried out using the hierarchical cluster methodology and taking into account the relevance of the results, a group of the states analysed in five clusters was chosen. In order to identify the method of testing the statistical significance of the membership of the analysed variables in the clusters, the homoscedasticity of the dispersions of the corresponding data series was verified. The results of Levene's test (Table 2) highlights the fact that for two of the six indicators under analysis, respectively BWFAP and GyWFIP, at a significance level $\alpha=0.05$, with a value of Sig.F < $\alpha$ (BWFAP - 0.006 and GyWFIP - 0.02), the null hypothesis $\mathrm{H}_{0}$ must be rejected and, consequently, the ANOVA methodology cannot be applied.

Under these conditions, the statistical significance testing of the membership of the variables in the clusters was performed using two tests, namely Welch and BrownForsythe. Following the application of the Welch test, the results show that for four of 
the analysed variables (BWFAP, BWFIP, GyWFIP, WP) Sig.F values are lower than $\alpha=0.05$, therefore, the null hypothesis $\mathrm{H} 0$ is rejected and, consequently, $\mathrm{H}_{0}$ is rejected, their environments differ significantly from one cluster to another.

Table 2. Results of Levene's tests to verify the homoscedaticity of the dispersions of the analysed data series. (Source: authors' own computations)

\begin{tabular}{c|c|c|c|c}
\hline \multirow{2}{*}{ Indicator } & \multirow{2}{*}{ Levene statistic } & \multicolumn{2}{|c|}{ Degrees of freedom } & \multirow{2}{*}{ Sig. } \\
\cline { 3 - 4 } & & $\mathrm{df} 1$ & $\mathrm{df} 2$ & .111 \\
\hline GWFAP & 2.189 & 4 & 18 & .006 \\
BWFAP & 5.207 & 4 & 18 & .799 \\
GyWFAP & .411 & 4 & 18 & .104 \\
BWFIP & 2.250 & 4 & 18 & .002 \\
GyWFIP & 6.407 & 4 & 18 & .146 \\
WP & 1.948 & 4 & 18 & \\
\hline
\end{tabular}

In Table 3 are presented the results of the robust tests of equality of means to verify the statistical significance of the membership of the variables in the clusters

Table 3. Results robust tests of equality of means to verify the statistical significance of the membership of the variables in the clusters. (Source: authors' own computations)

\begin{tabular}{|c|c|c|c|c|c|}
\hline \multirow{2}{*}{ Indicator } & \multirow{2}{*}{ Test } & \multirow{2}{*}{ Statistic $^{a}$} & \multicolumn{2}{|c|}{ Degrees of freedom } & \multirow{2}{*}{ Sig.F } \\
\hline & & & df1 & df 2 & \\
\hline \multirow{2}{*}{ GWFAP } & Welch & 4.520 & 4 & 7.119 & .039 \\
\hline & Brown-Forsythe & 4.946 & 4 & 11.968 & .014 \\
\hline \multirow{2}{*}{ BWFAP } & Welch & 25.796 & 4 & 6.816 & .000 \\
\hline & Brown-Forsythe & 106.924 & 4 & 4.317 & .000 \\
\hline \multirow{2}{*}{ GyWFAP } & Welch & 3.024 & 4 & 7.570 & .090 \\
\hline & Brown-Forsythe & 3.938 & 4 & 14.730 & .023 \\
\hline \multirow{2}{*}{ BWFIP } & Welch & 13.705 & 4 & 6.998 & .002 \\
\hline & Brown-Forsythe & 15.145 & 4 & 10.708 & .000 \\
\hline \multirow{2}{*}{ GyWFIP } & Welch & 11.815 & 4 & 7.781 & .002 \\
\hline & Brown-Forsythe & 9.487 & 4 & 5.261 & .013 \\
\hline \multirow{2}{*}{ WP } & Welch & 15.302 & 4 & 7.118 & .001 \\
\hline & Brown-Forsythe & 19.684 & 4 & 5.407 & .002 \\
\hline
\end{tabular}

${ }^{a}$ Asymptotically F distributed

Considering that for the GyWFAP variable, at the chosen significance threshold, the Welch test leads to the acceptance of the null hypothesis and its rejection for confidence level $90 \%(\alpha=0.10)$, and the Brown-Forsythe test indicates the rejection of the null hypothesis, we considered that this variable can also be taken into account when analysing the characteristics of the generated clusters.

Considering the values of the six variables considered in characterizing the sustainable water use by referring to the existence and water use resources in the economic sectors of agriculture and manufacturing in the 23 EU member countries, the 
structure and geographical distribution of the clusters is shown in Figure 5. The characteristics of the clusters are mainly highlighted by their classification in relation to the determined average values. The statistical characteristics associated to each cluster in terms of the analysed indicators is presented in Table 4.

\begin{tabular}{|cl|}
\hline Cluster & \multicolumn{1}{c|}{ Countries included } \\
\hline C1 & Denmark, Malta, UK \\
\hline C2 & $\begin{array}{l}\text { Croatia, Czech Republic, } \\
\text { Estonia, Latvia, Lithuania, } \\
\text { Slovakia, Sweden }\end{array}$ \\
\hline C3 & $\begin{array}{l}\text { Belgium, France, } \\
\text { Germany, Netherlands }\end{array}$ \\
\hline C4 & $\begin{array}{l}\text { Cyprus, Greece, Portugal, } \\
\text { Spain }\end{array}$ \\
\hline C5 & $\begin{array}{l}\text { Bulgaria, Hungary, Poland, } \\
\text { Romania, Slovenia }\end{array}$ \\
\hline
\end{tabular}

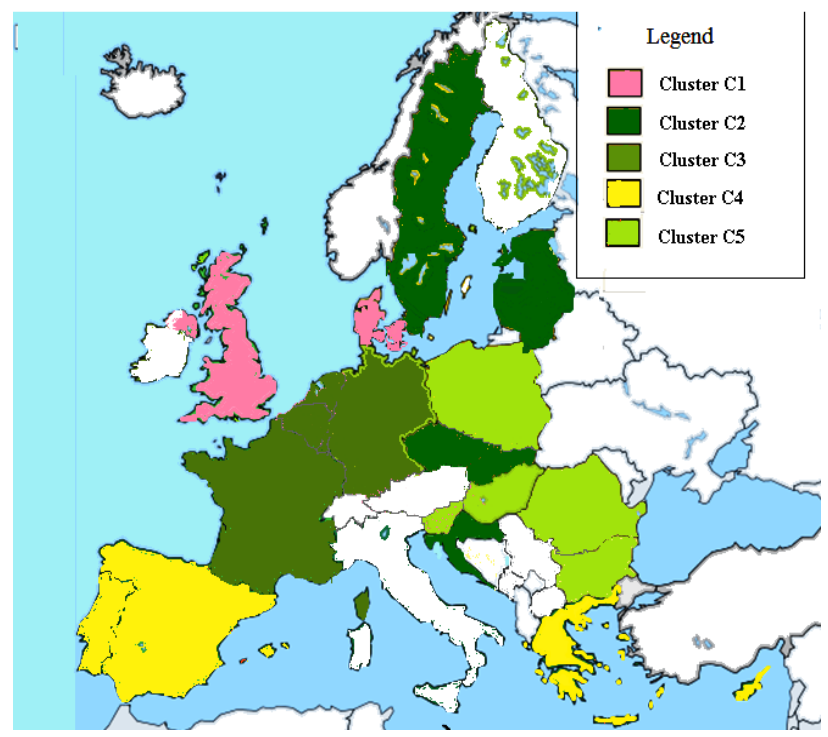

Figure 5. Cluster structure and geographic cluster distribution. (Source: authors' own design)

Table 4. Characteristics of the groups of countries according to the cluster average values of water footprint of consumption of agricultural and industrial products and water productivity. (Source: authors`own computations)

\begin{tabular}{|c|c|c|c|c|c|c|c|}
\hline \multirow[t]{2}{*}{ Cluster } & \multirow{2}{*}{$\begin{array}{l}\text { Number of } \\
\text { countries }\end{array}$} & \multicolumn{5}{|c|}{$\begin{array}{l}\text { Water footprint of agricultural and industrial products } \\
\qquad\left(\mathrm{m}^{3} / \mathrm{yr} / \mathrm{cap}\right)\end{array}$} & \multirow{2}{*}{ 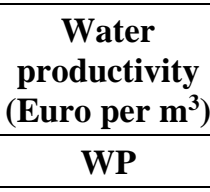 } \\
\hline & & GWFAP & BWFAP & GyWFAP & BWFIP & GyWFIP & \\
\hline $\mathrm{C} 1$ & 3 & 276.77 & 4.80 & 45.20 & 2.00 & 2.40 & 293.10 \\
\hline $\mathrm{C} 2$ & 7 & 821.21 & 2.11 & 94.31 & 2.13 & 9.73 & 106.11 \\
\hline C3 & 4 & 281.20 & 6.75 & 43.55 & 11.48 & 44.90 & 94.98 \\
\hline $\mathrm{C} 4$ & 4 & 739.13 & 197.08 & 79.70 & 2.85 & 7.70 & 45.30 \\
\hline C5 & 5 & 1072.22 & 8.18 & 148.06 & 10.50 & 92.98 & 29.22 \\
\hline
\end{tabular}

As can be seen from the data in Table 4, the average values of the six indicators (GWFAP, BWFAP, GyWFAP, BWFIP, GyWFIP, and WP) differ significantly, which means that there are major discrepancies between the 5 clusters formed.

While in cluster 1 , countries characterized by sustainable water use were identified, cluster 5 includes countries with significant water resources, but with a poor use of them. Denmark is part of Cluster 1, the European leader in water rationalization, whose main tools used to control water consumption are water prices and its metering. With an average GWFAP value far above all the other 4 clusters, which is almost 4 times higher than that of cluster 1 , cluster 5 has the lowest mean WP value. Also, cluster 5 has the highest average values for the other 2 indicators, respectively GyWFAP and GyWFIP. These countries must adopt and apply more drastic measures to solve the problem of 
pollution, to reduce the value of the gray water footprint of the consumption of agricultural and industrial products (Gogonea, 2019).

The positioning of the countries included in cluster 2 in areas with high rainfall, and on the other hand the abundance of lakes and rivers (Sweden, Slovakia, and Croatia) resulted in lower water consumption for agriculture, recording the lowest average BWFAP value among all clusters.

Cluster 3, consisting of countries with high operating indices (Belgium, France, Germany, Netherlands), recorded the highest average value of BWFIP, reflecting the predominant water use for consumption of industrial products.

Cluster 4 includes 4 countries in southern Europe (Cyprus, Greece, Portugal, Spain), large water-consuming countries, recording the highest average value of BWFAP. Also, the clustering of the states included in the analysis highlights the significant differences between them and in terms of existing long-term links between total internal water footprint (TWF) and water productivity (WP), and also between total internal water footprint for industrial products (TotalIND) and total internal water footprint for agricultural products (TotalAGR).

Thus, from the point of view of existing long-term relations between WP and TWP (Fig. 6), the large gap must be noted between Denmark, Malta, UK (countries included in cluster 1) and the other 20 countries in terms of water productivity. Also, Belgium, France, Germany and The Netherlands, although they are far from Denmark, Malta, and UK in terms of water productivity, hold a special position compared to the countries included in clusters $\mathrm{C} 2, \mathrm{C} 4$ and $\mathrm{C} 5$, due to the fact that the average value of TWF $\left(393.38 \mathrm{~m}^{3} / \mathrm{yr} / \mathrm{cap}\right)$ is less than half of the average values of TWF recorded in them.

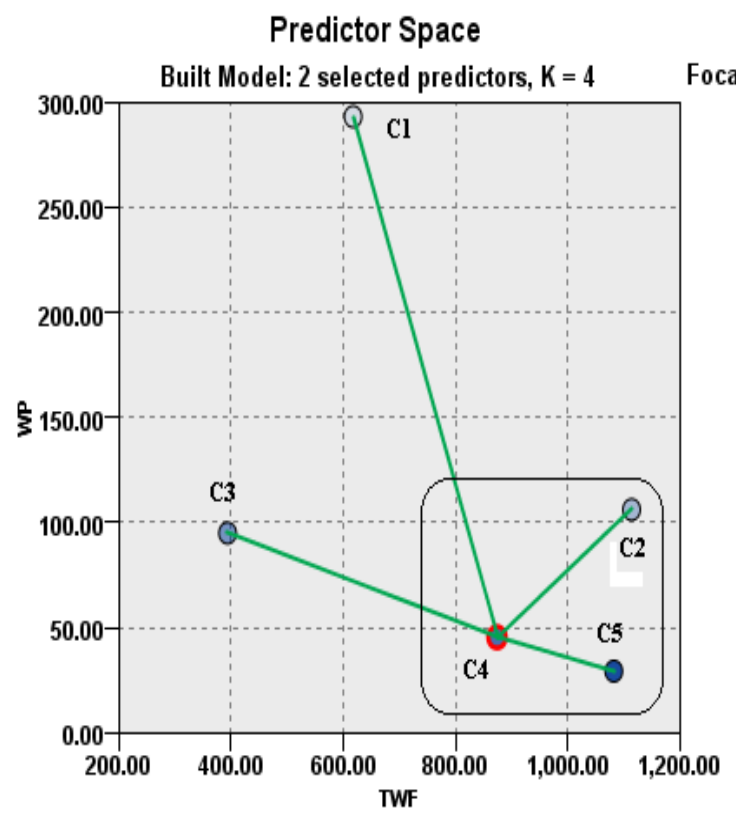

Peers Chart

Focal Records and Nearesi Neighbors
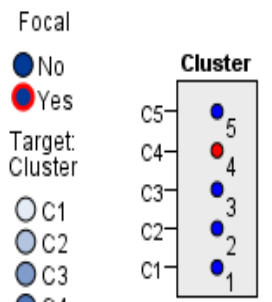

$\mathrm{OC4}$

$\mathrm{OC5}$
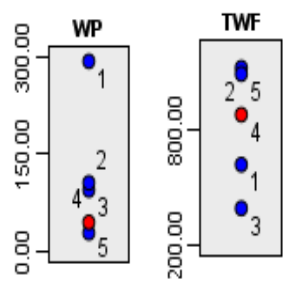

Figure 6. The highlighting of the distances between clusters according to WP (euro $\left.\mathrm{m}^{3}\right)$ and TWF ( $\left.\mathrm{m}^{3} / \mathrm{yr} / \mathrm{cap}\right)$. (Source: authors' own design)

Another significant analysis of the clusters also includes a graphical representation (Fig. 7) through which the distances between the clusters according to WP (euro/ $\mathrm{m}^{3}$ ), TotalIND ( $\left.\mathrm{m}^{3} / \mathrm{yr} / \mathrm{cap}\right)$ and TotalAGR $\left(\mathrm{m}^{3} / \mathrm{yr} / \mathrm{cap}\right)$ are highlighted. 
Predictor Space

Built Model: 3 selected predictors, $K=4$

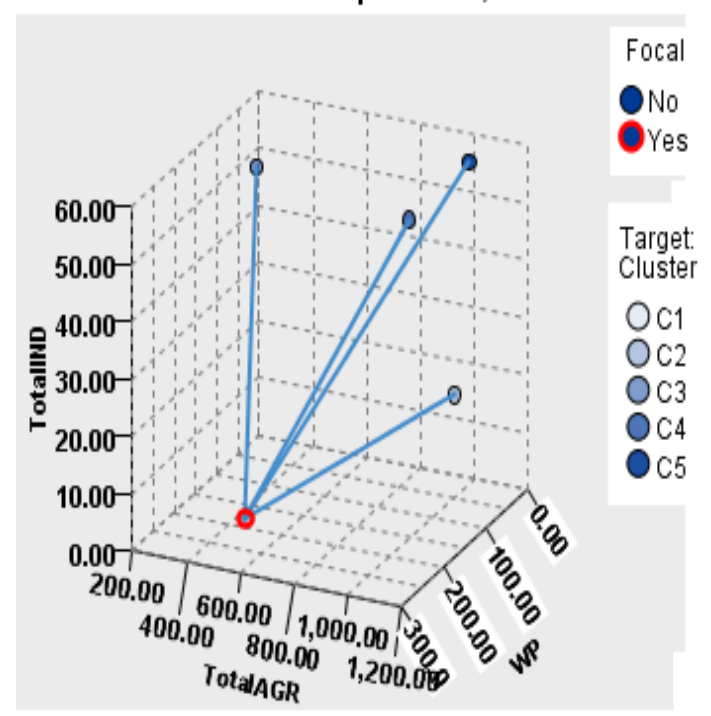

Peers Chart

Focal Records and Nearest Neighbors
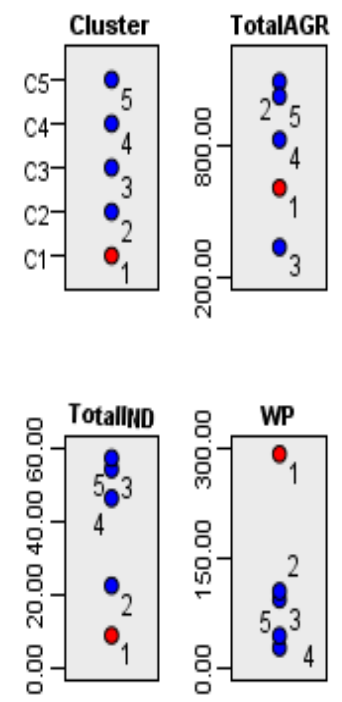

Figure 7. The highlighting of the distances between clusters according to WP $\left(e u r o / m^{3}\right)$, TotalIND $\left(\mathrm{m}^{3} / \mathrm{yr} / \mathrm{cap}\right)$ and TotalAGR $\left(\mathrm{m}^{3} / \mathrm{yr} / \mathrm{cap}\right)$. (Source: authors' own design)

In terms of the dependencies between water productivity, total water footprint for industrial products (TotalIND) and total internal water footprint for agricultural products (TotalAGR), in this case the countries included in the $\mathrm{C} 1$ cluster (Denmark, Malta, UK) are significantly different from the others countries included in the analysis. The difference is evident not only in terms of WP values, but also in the fact that the lowest average value of TotalIND $\left(9.16 \mathrm{~m}^{3} / \mathrm{yr} / \mathrm{cap}\right)$ is recorded here, 2.5 times lower than in the $\mathrm{C} 2$ cluster and over 5 times smaller than in clusters $\mathrm{C} 3, \mathrm{C} 4$ and $\mathrm{C} 5$.

From the point of view of TotalAGR, the closest to the $\mathrm{C} 1$ cluster is the $\mathrm{C} 4$ cluster (Cyprus, Greece, Portugal, Spain) with an average value of $827.13 \mathrm{~m}^{3} / \mathrm{yr} / \mathrm{cap}$ (with $218.96 \mathrm{~m}^{3} / \mathrm{yr} / \mathrm{head}$ more than in Cluster $\mathrm{C} 1$ ). On the other hand, Cluster $\mathrm{C} 3$ also occupies a separate place, being the only one where the TotalAGR has a lower value than Cluster C1 (338.87 $\mathrm{m}^{3} / \mathrm{yr} / \mathrm{cap}$, compared to $\left.608.17 \mathrm{~m}^{3} / \mathrm{yr} / \mathrm{cap}\right)$.

However, if we consider the TotalIND values, the closest one to Cluster $\mathrm{C} 1$ is Cluster C2 (Croatia, Czech Republic, Estonia, Latvia, Lithuania, Slovakia, Sweden) with an average value of TotalIND of $22.74 \mathrm{~m}^{3} / \mathrm{yr} / \mathrm{cap}$ (with $13.57 \mathrm{~m}^{3} / \mathrm{yr} / \mathrm{cap}$ more than in Cluster $\mathrm{C} 1$ ). At the same time, Clusters $\mathrm{C} 3, \mathrm{C} 4$ and $\mathrm{C} 5$ form a fairly tight group with values of TotalIND ranging from $46.58 \mathrm{~m}^{3} / \mathrm{yr} /$ cap (cluster C4) to $57.5 \mathrm{~m}^{3} / \mathrm{yr} /$ cap (cluster C5).

Summarizing the performed analysis, the usefulness of continuous monitoring and study of the efficiency of the use of water resources can serve to identify efficiency as clearly as possible at territorial level, this being considered a significant indicator for the description of water use in agricultural and industrial production (Gang et al., 2016; Huang et al., 2017).

\section{Conclusions}

Considering that the two economic branches use the three categories of water (Green, Blue, Gray), the analysis in this research is realised taking into account the 
interdependencies of all types of water. Thus, five other study variables (Green, Blue, Gray water footprint of consumption of agricultural products and Blue, Gray water footprint of consumption of industrial products) were introduced into the research.

In Europe, for all the 23 countries included in the study, for the agricultural sector, on average per year, approximately one third of the available water is used. The irrigation of agricultural crops differs from one country to another, mainly due to climatic conditions, but also to the technological systems in place. Different characteristics are also noticeable in what regards the manufacturing technologies used by each European country, which has determined the detection of different consumption patterns, with quite significant differences from one country to another.

Northern and Western European countries are characterized by abundant rainfalls that form the basis of their water resources, paralleled by a high degree of water rationalization, while in Central and Southern Europe we either have countries with rich water reserves, but poor use of them (Bulgaria, Hungary, Poland, Romania, Slovenia), or countries with arid or semi-arid conditions requiring the use of irrigation in a large proportion (Cyprus, Greece, Spain). Thus, many countries in southern Europe, with limited resources, have to cope with a high water pressure due to the strongly developed agri-food system, while other countries have considerably reduced water consumption in manufacturing through advanced technologies. In both manufacturing and agriculture, the biggest water consumers are: Belgium, France and Bulgaria, while Malta is the country with the highest volume of imported water.

The results obtained from the application of the analysis (another analysed object) emphasize the same aspects of the territorial concentration of water types in countries. The six clusters formed complement the analysis of the relations between the indices of water exploitation and its productivity, as well as the relations between the internal water footprints used for the production of agricultural and industrial products, with the identification and the evaluation of some possible relations between the internal water footprint used for the production of products and the efficiency of its use. The highest average value of water productivity in the European Union was recorded by Cluster 1 (Denmark, Malta and UK), while southern countries remain in cluster 5, characterized by low performances in terms of sustainable water use. In this context, in the future, a priority for the countries, in relation to the problems they are facing, would be their orientation towards the cultivation of less water-consuming plants, and technologies which will sharply reduce the water consumption in the industry.

The EU countries must join efforts in the direction of water saving, its efficient use, thus following in the direction of sustainable development. As a consequence of the application of the quantitative descriptive method between the water reserves of each state and the efficiency of the water quantities used, it was observed that, in general, the efficiency of the water use does not depend to a large extent on the restrictive nature of the resource.

The results of this research allow us to conclude that water-related problems may hamper severely the economic development of a region or country, depending on the availability of this resource, or on the degree of accessibility to it. Other studies as Ibáñez et al. (2017) emphasise that water footprint could be used to identify the main environmental impacts on the high risks areas. In the same time water resources could become an important and restrictive factor to social and economic growth in numerous countries as Li et al. (2021) highlights. 
Indicators like water productivity, water exploitation and water footprint may reflect accurately the level of development of the two economic sectors considered in our study, agriculture and manufacturing, and, as such, the three indicators can guide towards developing and enforcing appropriate measures to save water and, thereby, reduce the level of gray water in the manufacturing and farming production chains. The assessment of resilient development and of the efficiency of an environmental policy with the help of the water footprint and of other, related, indicators, opens a broad field of interdisciplinary research against the background of ever wider analyses purporting to identify new indicators for the sustainable development of contemporary economies. The application of the water productivity, exploitation and footprint indicators develop new approaches and highlight the global dimension on the water management strategies and offers in an equal measure a better understanding of the countries` dependence on water resources and their usage. This study argues a proactive need for a more rationalallocative and intelligent water usage in competitive economies. In this context, in literature is a massive need for future studies in assessing the environmental performance by evaluating water indicators. Developing a specific framework in assessing water performance and consumptions patterns would be one of the major challenges in the near future. In this context, this paper may serve as a basic instrument in building the structure required to understand concepts and principles like impartiality and efficiency in the use of water, sustainability of water exploitation, and the rational management of water as an effect of using specific indicators, such as those generated by the water footprint system.

\section{Research limits and further directions of investigation}

Understanding the mechanisms that foster sustainable development, and the extensive use of the indicators that come to our aid in doing so require a minute analysis of the existing literature covering this subject, and, no less, the functional relations of the available statistic data used to substantiate the propounded methodology and research model. In view of the above, our research attempts to answer the question to what extent the three indicators examined herein - water productivity, water exploitation and water footprint - are obsolete concepts or representative tools in understanding environmental policy?

Our research follows the current trends in the literature aiming the water economics. Notwithstanding, our study has its own limitations deriving from the very working model and variables chosen for the purpose. Among the main limitations are the number of variables used and the relatively small reference span. Also, the fact that the cluster model is based only on the values of a single year. These limits however may become the starting point of new lines of investigation for future studies. One other limitation arises from the understanding and implementation of the concepts employed, and from the fact that the results obtained cannot be statistically extrapolated, despite the highly explanatory nature of the model and methodology applied.

\section{REFERENCES}

[1] Ababaei, B., Etedali, H. R. (2017): Water footprint assessment of main cereals in Iran. Agricultural Water Management 179: 401-411. 
[2] Aldaya, M. M., Martínez-Santos, P., Llamas, M. R. (2010): Incorporating the water footprint and virtual water into policy: reflections from the Mancha Occidental Region, Spain. - Water Resources Management 24(5): 941-958.

[3] Andrei, J. V., Patrascu, A., Drăgoi, M. C., Gogonea, R. M., Zaharia, R. S. (2018): Using total water footprint of national consumption as sustainable development indicator-a critical review. - Ekonomika Poljoprivrede 65(4).

[4] Andrei, J. V., Gogonea, R. M., Zaharia, M., Patrascu, A., Bălăcescu, A., Ladaru, R. G. (2020): A Critical Approach on using total water footprint of agricultural products as a potential sustainable development indicator. - Tehnički Vjesnik 27(2): 671-679.

[5] Ansorge, L., Beránková, T. (2017): LCA water footprint AWARE characterization factor based on local specific conditions. - European Journal of Sustainable Development 6(4): 13-13.

[6] Arnell, N. W., van Vuuren, D. P., Isaac, M. (2011): The implications of climate policy for the impacts of climate change on global water resources. - Glob. Environ. Change 21: 592-603. https://doi.org/10.1016/j.gloenvcha.2011.01.015.

[7] Barbosa, E. A. A., Matsura, E. E., dos Santos, L. N. S., Gonçalves, I. Z., Nazário, A. A., Feitosa, D. R. C. (2017): Water footprint of sugarcane irrigated with treated sewage and freshwater under subsurface drip irrigation, in Southeast Brazil. - Journal of Cleaner Production 153: 448-456.

[8] Borsato, E., Tarolli, P., Marinello, F. (2018): Sustainable patterns of main agricultural products combining different footprint parameters. - Journal of Cleaner Production 179: 357-367.

[9] Burchart-Korol, D., Kruczek, M. (2015): Water scarcity assessment of steel production in national integrated steelmaking route. - Metalurgija 54(1): 276-278.

[10] Chapagain, A. K., Tickner, D. (2012): Water footprint: help or hindrance? - Water Alternatives 5(3): 563.

[11] Chen, B., Han, M. Y., Peng, K., Zhou, S. L., Shao, L., Wu, X. F., .. \& Chen, G. Q. (2018): Global land-water nexus: agricultural land and freshwater use embodied in worldwide supply chains. - Science of the Total Environment 613: 931-943.

[12] Chiu, C. C., Shiang, W. J., Lin, C. J., Wang, C. H., Chang, D. M. (2015): Water footprint analysis of second-generation bioethanol in Taiwan. - Journal of Cleaner Production 101: 271-277.

[13] Clar, E.; Martín-Retortillo, M.; Pinilla, V. (2018): The Spanish path of agrarian change, 1950-2005: From authoritarian to export-oriented productivism. - Journal of Agrarian Change; 18: 324-347.

[14] D'Ambrosio, E., Ricci, G. F., Gentile, F., De Girolamo, A. M. (2020): Using water footprint concepts for water security assessment of a basin under anthropogenic pressures. - Science of the Total Environment 748: 141356.

[15] de Miguel, Á., Hoekstra, A. Y., García-Calvo, E. (2015): Sustainability of the water footprint of the Spanish pork industry. - Ecological Indicators 57: 465-474.

[16] de Ruiter, H., Macdiarmid, J. I., Matthews, R. B., Kastner, T., Lynd, L. R., Smith, P. (2017): Total global agricultural land footprint associated with UK food supply 19862011. - Global Environmental Change 43: 72-81.

[17] Dietzel, R., Liebman, M., Ewing, R., Helmers, M., Horton, R.., Jarchow, M., Archontoulis, S. (2016): How efficiently do corn-and soybean-based cropping systems use water? A systems modelling analysis. - Global Chang. Biol. 22(2): 666-681.

[18] Dourte, D. R., Fraisse, C. W., Uryasev, O. (2014): WaterFootprint on AgroClimate: a dynamic, web-based tool for comparing agricultural systems. - Agricultural Systems 125: $33-41$.

[19] EESC (2013): A Blueprint to Safeguard Europe's Water Resources. - NAT/593, European Economic and Social Committee, Brussels, 10 July 2013. 
[20] EUROSTAT (2020a): Water Exploitation Index. https://ec.europa.eu/eurostat/databrowser/view/SDG_06_60/default/table. Accessed: 02.13.2020.

[21] EUROSTAT (2020b): Water Productivity. https://ec.europa.eu/eurostat/databrowser/view/T2020_RD210/default/table. Accessed: 02.13.2020.

[22] Ewaid, S. H., Abed, S. A., Al-Ansari, N. (2019): Water footprint of wheat in Iraq. Water 11(3): 535.

[23] Gang, C., Wang, Z., Chen, Y., Yang, Y., Li, J., Cheng, J.,... \& Odeh, I. (2016): Droughtinduced dynamics of carbon and water use efficiency of global grasslands from 2000 to 2011. - Ecological Indicators 67: 788-797.

[24] Garofalo, P., Ventrella, D., Kersebaum, K. C., Gobin, A., Trnka, M., Giglio, L., ... \& Castellini, M. (2019): Water footprint of winter wheat under climate change: trends and uncertainties associated to the ensemble of crop models. - Science of the Total Environment 658: 1186-1208.

[25] Gerbens-Leenes, P. W., Hoekstra, A. Y., Bosman, R. (2018): The blue and grey water footprint of construction materials: steel, cement and glass. - Water Resources and Industry 19: 1-12.

[26] Gogonea, R. M. (2019): Water footprint for industrial products. A paradigm of concentration. - Journal of Research and Innovation for Sustainable Society 1(1): 123130.

[27] Gómez-Llanos, E., Durán-Barroso, P., Robina-Ramírez, R. (2020): Analysis of consumer awareness of sustainable water consumption by the water footprint concept. - Science of the Total Environment 137743.

[28] Gu, Y., Xu, J., Keller, A. A., Yuan, D., Li, Y., Zhang, B., ... \& Li, F. (2015): Calculation of water footprint of the iron and steel industry: a case study in Eastern China. - Journal of Cleaner Production 92: 274-281.

[29] Harding, K. G. (2019): And now to confuse you! How is the public expected to understand water footprinting metrics? - Procedia Manufacturing 35: 731-736.

[30] He, Y., Wang, Y., Chen, X. (2019): Spatial patterns and regional differences of inequality in water resources exploitation in China. - Journal of Cleaner Production 227: 835-848.

[31] Hernández, M., Echarte, L., Della Maggiora, A., Cambareri, M., Barbieri, P., Cerrudo, D. (2015): Maize water use efficiency and evapotranspiration response to $\mathrm{N}$ supply under contrasting soil water availability. - Field Crops Research 178: 8-15.

[32] Hoekstra, A. Y. (2003): Virtual water trade: proceedings of the international expert meeting on virtual water trade. - Delft, The Netherlands, 12-13 December 2002, Value of Water Research Report Series No. 12.

[33] Hoekstra, A. Y., Chapagain, A. K. (2006): Water Footprints of Nations: Water Use by People as a Function of Their Consumption Pattern. - In: Craswell, E. et al. (eds.) Integrated Assessment of Water Resources and Global Change. Springer, Dordrecht, pp. $35-48$.

[34] Hoekstra, A., Mekonnen, M. (2012): The water footprint of humanity. - PNAS 109(9): 3232-3237. https://doi.org/10.1073/pnas.1109936109.

[35] Hogeboom, R. J. (2020): The water footprint concept and water's grand environmental challenges. - One Earth 2(3): 218-222.

[36] Huang, L., He, B., Han, L., Liu, J., Wang, H., Chen, Z. (2017): A global examination of the response of ecosystem water-use efficiency to drought based on MODIS data. Science of the Total Environment 601: 1097-1107.

[37] Ibáñez, G. R., Ruíz, J. M., Sánchez, M. R., López, J. C. (2017): A corporate water footprint case study: the production of Gazpacho, a chilled vegetable soup. - Water Resources and Industry 17: 34-42.

[38] Jamshidi, S. (2019): An approach to develop grey water footprint accounting. Ecological Indicators 106: 105477. 
[39] Jean, V., Patrascu, A., Drăgoi, M., Rodica-Manuela, G., Radu, S. (2018): Using total water footprint of national consumption as sustainable development indicator: a critical review. - Ekonomika Poljoprivrede 65(4): 1427-1447.

[40] Jeswani, H. K., Azapagic, A. (2011): Water footprint: methodologies and a case study for assessing the impacts of water use. - Journal of Cleaner Production 19(12): 1288-1299.

[41] Kubová, P., Hájek, M., Třebický, V. (2018): Carbon footprint measurement and management: case study of the school forest enterprise. - BioResources 13(2): 45214535 .

[42] Lee, S. H., Choi, J. Y., Yoo, S. H., Kim, Y. D., Shin, A. (2015): Estimation of water footprint for livestock products in Korea. - Journal of the Korean Society of Agricultural Engineers 57(2): 85-92.

[43] Li, M., Xu, Z., Jiang, S., Zhuo, L., Gao, X., Zhao, Y., Liua, Y., Wang, W., Jin, J., Wu, P. (2021): Non-negligible regional differences in the driving forces of crop-related water footprint and virtual water flows: a case study for the Beijing-Tianjin-Hebei region. Journal of Cleaner Production 279: 123670.

[44] Lipińska, D. (2016): Resource-efficient growth in the EU's Sustainable development - a comparative analysis based on selected indicators. - Comparative Economic Research 19(1): 101-117.

[45] Lovarelli, D., Bacenetti, J., Fiala, M. (2016): Water Footprint of crop productions: a review. - Science of the Total Environment 548: 236-251.

[46] Ma, X., Ye, L., Qi, C., Yang, D., Shen, X., Hong, J. (2018): Life cycle assessment and water footprint evaluation of crude steel production: a case study in China. - Journal of Environmental Management 224: 10-18.

[47] Marinoiu, C. (2016): Bootstrap stability evaluation and validation of clusters based on agricultural indicators of EU countries. - Economic Insights - Trends and Challenges V(LXVIII): 65-72.

[48] Mekonnen, M. M., Hoekstra, A. Y. (2011): National water footprint accounts: the green, blue and grey water footprint of production and consumption. - Value of Water Research Report Series No. 50, UNESCO-IHE, Delft, the Netherlands. https://waterfootprint.org/media/downloads/Report50-NationalWaterFootprints-Vol1.pdf. Accessed: 02.22.2019.

[49] Miglietta, P. P., Toma, P., Fanizzi, F. P., De Donno, A., Coluccia, B., Migoni, D., ... \& Serio, F. (2017): A grey water footprint assessment of groundwater chemical pollution: case study in Salento (southern Italy). - Sustainability 9(5): 799.

[50] Mourad, R., Jaafar, H. H., Daghir, N. (2019): New estimates of water footprint for animal products in fifteen countries of the Middle East and North Africa (2010-2016). - Water Resources and Industry 22: 100113.

[51] Oki, T., Kanae, S. (2006): Global hydrological cycles and world water resources. Science 313(5790): 1068-1072.

[52] Owusu-Sekyere, E., Scheepers, M. E., Jordaan, H. (2016): Water footprint of milk produced and processed in South Africa: implications for policy-makers and stakeholders along the dairy value chain. - Water 8(8): 322.

[53] Page, G., Ridoutt, B., Bellotti, B. (2012): Carbon and water footprint trade-offs in fresh tomato production. - Journal of Cleaner Production 32: 219-226.

[54] Poom, A., Orru, K., Ahas, R. (2017): The carbon footprint of business travel in the knowledge-intensive service sector. - Transportation Research Part D: Transport and Environment 50: 292-304.

[55] Raskin, P.; Gleick, P. H.; Kirshen, P.; Pontius, R. G. Jr, Strzepek, K. (1997): Comprehensive assessment of the freshwater resources of the world. - Stockholm Environmental Institute, Sweden. Document prepared for the fifth session of the United Nations Commission on Sustainable Development. 
[56] Roibás, L., Elbehri, A., Hospido, A. (2015): Evaluating the sustainability of Ecuadorian bananas: carbon footprint, water usage and wealth distribution along the supply chain. Sustainable Production and Consumption 2: 3-16.

[57] Schäfer, F., Blanke, M. (2012): Farming and marketing system affects carbon and water footprint - a case study using Hokkaido pumpkin. - Journal of Cleaner Production 28: 113-119.

[58] Scheepers, M. E., Jordaan, H. (2016): Assessing the blue and green water footprint of lucerne for milk production in South Africa. - Sustainability 8(1): 49.

[59] Schlegel, T., Puiatti, D., Ritter, H. J., Lesueur, D., Denayer, C., Shtiza, A. (2016): The limits of partial life cycle assessment studies in road construction practices: a case study on the use of hydrated lime in Hot Mix Asphalt. - Transportation Research Part D: Transport and Environment 48: 141-160.

[60] Serio, F., Miglietta, P. P., Lamastra, L., Ficocelli, S., Intini, F., De Leo, F., De Donno, A. (2018): Groundwater nitrate contamination and agricultural land use: a grey water footprint perspective in Southern Apulia Region (Italy). - Science of the Total Environment 645: 1425-1431.

[61] Serrano, A., Guan, D., Duarte, R., Paavola, J. (2016): Virtual water flows in the EU27: a consumption-based approach. - Journal of Industrial Ecology 20(3): 547-558.

[62] Sheikhipour, B., Javadi, S., Banihabib, M. E. (2018): Assessing the effectiveness of aquifer regeneration scenarios by Sustainability Index and water exploitation indicators of water resources, case study: Shahrekord aquifer. - Journal of Water and Soil 32(2).

[63] Sima, V., Gheorghe, I. G. (2015): Challenges and opportunities of the ecological footprinting in Romania. - Annals of the „Constantin Brancusi” University of Targu Jiu, Economy Series 2015(Special Issue): 108-113.

[64] Stoessel, F., Juraske, R., Pfister, S., Hellweg, S. (2012): Life cycle inventory and carbon and water foodprint of fruits and vegetables: application to a Swiss retailer. Environmental Science \& Technology 46(6): 3253-3262.

[65] Suttayakul, P., Aran, H., Suksaroj, C., Mungkalasiri, J., Wisansuwannakorn, R., Musikavong, C. (2016): Water footprints of products of oil palm plantations and palm oil mills in Thailand. - Science of the Total Environment 542: 521-529.

[66] Tata Steel (2013): Water Footprint Assessment Tata Chemicals, Tata Motors, Tata Power, Tata Steel: Results \& Learning. June 2013. - IFC, Washington, DC.

[67] Vanham, D. (2016): Does the water footprint concept provide relevant information to address the water-food-energy-ecosystem nexus? - Ecosystem Services 17: 298-307.

[68] Visentin, J. C., Guilhoto, J. J. M. (2019): The role of interregional trade in virtual water on the blue water footprint and the water exploitation index in Brazil. - Review of Regional Studies 49(2): 299-322.

[69] Vörösmarty, C. J., Hoekstra, A. Y., Bunn, S. E., Conway, D., Gupta, J. (2015): Fresh water goes global. - Science 349(6247): 478-479.

[70] Wada, Y., Flörke, M., Hanasaki, N., Eisner, S., Fischer, G., Tramberend, S., Satoh, Y., van Vliet, M., Yillia, P., Ringler, C., Wiberg, D., Burek, P. (2016): Modeling global water use for the 21st century: the Water Futures and Solutions (WFaS) initiative and its approaches. - Geoscientific Model Development 9(1): 175-222.

[71] Winpenny, J. (2005): Managing Water as an Economic Resource. - Routledge, London.

[72] Xiao, G., Zheng, F., Qiu, Z., Yao, Y. (2013): Impact of climate change on water use efficiency by wheat, potato and corn in semiarid areas of China. - Agriculture, Ecosystems \& Environment 181: 108-114.

[73] Zhao, C., Chen, B. (2014): Driving force analysis of the agricultural water footprint in China based on the LMDI method. - Environmental Science \& Technology 48(21): 12723-12731.

[74] Zonderland-Thomassen, M. A., Ledgard, S. F. (2012): Water footprinting-A comparison of methods using New Zealand dairy farming as a case study. - Agricultural Systems 110: 30-40. 
[75] Zoumides, C., Bruggeman, A., Hadjikakou, M., Zachariadis, T. (2014): Policy-relevant indicators for semi-arid nations: the water footprint of crop production and supply utilization of Cyprus. $\quad$ Ecological Indicators 43: 205-214. http://dx.doi.org/10.13023/ETD.2016.234. 